\title{
Immobilization of Lysozyme on Biomass Charcoal Powder Derived from Plant Biomass Wastes
}

\author{
Hidetaka Noritomi $^{{ }^{*}}$, Reona Ishiyama ${ }^{1}$, Ryotaro Kai ${ }^{1}$, Daiki Iwai ${ }^{1}$, Masahiko Tanaka ${ }^{2}$, Satoru Kato ${ }^{1}$ \\ ${ }^{1}$ Department of Applied Chemistry, Tokyo Metropolitan University, Tokyo, Japan; ${ }^{2}$ EEN Co., Ltd., Tokyo, Japan. \\ Email: "noritomi@tmu.ac.jp
}

Received August $16^{\text {th }}, 2012$; revised September 27 $7^{\text {th }}, 2012$; accepted October $5^{\text {th }}, 2012$

\begin{abstract}
Biomass charcoal powder (BCP) was used as a carrier matrix for immobilization of chicken egg white lysozyme. BCP was derived from plant biomass wastes such as dumped adzuki beans by pyrolysis without combustion under nitrogen atmosphere and grinding with a jet mill. The amount of lysozyme immobilized on BCP of adzuki beans by adsorption was $11 \mu \mathrm{mol} / \mathrm{g}(0.16 \mathrm{~g} / \mathrm{g})$ at $\mathrm{pH} 7.0$. The optimum $\mathrm{pH}$ values for free and immobilized lysozyme activities were 6.8 and 7.2 , respectively. The optimum temperature for both free and immobilized lysozyme activities was $25^{\circ} \mathrm{C}$. The half-life of immobilized lysozyme exhibited 1.8-fold compared to that of free lysozyme at $5^{\circ} \mathrm{C}$. Moreover, the half life of immobilized lysozyme was 7 times greater than that of lysozyme at $90^{\circ} \mathrm{C}$.
\end{abstract}

Keywords: Immobilization; Biomass Charcoal Powder; Lysozyme; Activity; Stability

\section{Introduction}

Immobilization of enzymes onto various water-insoluble carriers has attracted continuous attention in the fields of biotechnology, fine chemistry, pharmaceutical, and biosensor [1,2]. Some of desired carrier characteristics are indicated as follows: 1) large surface area; 2) permeability; 3) hydrophilic character; 4) insolubility; 5) chemical, mechanical, and thermal stability; 6) high rigidity; 7) suitable shape and particle size; 8) resistance to microbial attack; 9) regenerability; 10) low cost. Various solid materials such as natural polymers, proteins, synthetic polymers, minerals, and fabricated materials have so far been proposed as a carrier. It has been well known that the performances of immobilized enzyme such as activity, specificity, and stability largely depend on the structure of supports and the method of immobilization. On the other hand, the development of technologies for recycling wastes is one of the most important challenges to establish recycling society. Wastes are carbonized to be applied to humidity material, and activated carbons $[3,4]$. Specifically, much attention has been paid on the charcoal produced from plant biomass wastes by means of pyrolysis in order to amend the soil, since it exhibits the excellent priming effect [5]. When the charcoal prepared from plant biomass wastes is used as a soil modifier, it has been called biochar. However, plant biomass wastes

*Corresponding author. have not sufficiently been recycled yet, compared to other wastes, although an enormous amount of plant biomass wastes has been discharged in the world. Moreover, the development in the high value-added function of charcoal of plant biomass wastes has been desired.

Immobilization of enzymes has been performed by means of adsorption, covalent binding, entrapment, encapsulation, crosslinking, and so on. Among these methods, immobilization of enzymes by adsorption has been considered as the simplest and most economical method. Moreover, enzymes immobilized through adsorption have the benefit of wide applicability, since they may keep their native structures and functions.

In the present work, the finely grinded biomass charcoal powder (BCP) was derived from plant biomass wastes such as dumped adzuki beans by pyrolysis without combustion under nitrogen atmosphere and grinding with a jet mill. In order to assess whether BCP is suitable as a carrier, we have investigated the effects of $\mathrm{pH}$ and temperature on the activity and stability of enzymes on BCP. As a model protein, chicken egg-white lysozyme has been employed, since it is well investigated regarding its structure, properties, and functions [6].

\section{Materials and Method}

\subsection{Materials}

Lysozyme from chicken egg white (EC 3.2.1.17, 46400 units/mg solid, MW = 14300, pI = 11) and Micrococcus 
lysodeikticus (ATCC No. 4698) were purchased from Sigma-Aldrich Co. (St. Louis, USA).

\subsection{Preparation of Biomass Charcoal Powder}

Under nitrogen atmosphere, dumped adzuki beans were dried at $180^{\circ} \mathrm{C}$ for $2 \mathrm{hr}$, were pyrolyzed at $450^{\circ} \mathrm{C}$ for $2 \mathrm{hr}$, were carbonized at $350^{\circ} \mathrm{C}$ for $3 \mathrm{hr}$, and were then cooled at $100^{\circ} \mathrm{C}$ for $1 \mathrm{hr}$ by pyrolyzer (EE21 Pyrolyzer, EEN Co. Ltd., Japan). Biomass charcoal powder (BCP) was obtained by grinding the resultant biomass charcoal (BC) with jet mill (100 AS, Fuji Sangyo Co. Ltd., Japan).

\subsection{Characterization of BCP}

All samples were outgassed at $200^{\circ} \mathrm{C}$ for $15 \mathrm{hr}$ prior to the carbon dioxide adsorption measurements. The specific surface area of BCP was calculated with use of the Brunauer-Emmett-Teller (BET) method using a micropore system (ASAP2010, Shimadzu Co. Ltd., Japan).

The $\zeta$ potentials for biomass charcoal powder were measured by electrophoretic light scattering (ELS-Z2, OTSUKA Electronics Co. Ltd., Japan).

The SEM micrograph was obtained using a scanning electron microscope (JSM-7500FA, JEOL, Japan) operating at $15 \mathrm{kV}$. The sample for SEM was prepared on a carbon tape without vapor deposition.

The surface of BCP was analyzed by $\mathrm{x}$-ray photoelectron spectroscopy (XPS) (Quantum-2000, ULVAC-PHI Co. Ltd., Japan) operating at X-ray beam size of $100 \mu \mathrm{m}$.

\subsection{Immobilization of Lysozyme onto BCP}

As a typical procedure, $0.01 \mathrm{M}$ phosphate buffer solution at pH 7 containing $500 \mu \mathrm{M}$ lysozyme and $3 \mathrm{~g} / \mathrm{L} \mathrm{BCP}$ of adzuki beans was incubated at $25^{\circ} \mathrm{C}$ and $120 \mathrm{rpm}$ for 24 hr. After adsorption, the mixture was filtrated with a membrane filter (pore size: $0.1 \mu \mathrm{m}$, Millipore Co. Ltd., USA). The amount of lysozyme adsorbed on BCP was calculated by subtracting the amount of lysozyme included in the supernatant liquid after adsorption from the amount of lysozyme in its aqueous solution before adsorption. The amount of lysozyme was measured at 280 $\mathrm{nm}$ by UV/vis spectrophotometer (UV-1800, Shimadzu Co. Ltd., Japan).

\subsection{Measurement of Activity of Free and Immobilized Lysozyme}

Lysozyme activity was determined using Micrococcus lysodeikticus as a substrate [7]. Three hundred and fifty $\mu \mathrm{L}$ of $0.01 \mathrm{M}$ phosphate buffer solution at $\mathrm{pH} 6.2$ or 7.0 of free and immobilized lysozyme $(33 \mu \mathrm{M})$ was added to 21 $\mathrm{mL}$ of $0.01 \mathrm{M}$ phosphate buffer solution at $\mathrm{pH} 6.2$ or 7.0 containing $200 \mathrm{mg} / \mathrm{L}$ Micrococcus lysodeikticus, and the mixture was incubated by stirring at $25^{\circ} \mathrm{C}$. The absorbance of the mixture was periodically measured at $450 \mathrm{~nm}$ by UV/vis spectrophotometer (UV-1800, Shimadzu Co. Ltd.).

\subsection{Effect of pH on Activity of Free and Immobilized Lysozyme}

The effect of $\mathrm{pH}$ on the activity of free and immobilized lysozyme was assayed in the $\mathrm{pH}$ range from 5.0 to 9.0 at $25^{\circ} \mathrm{C}$. The buffer solutions used in the present work were an acetate buffer solution at $\mathrm{pH} 5$, phosphate buffer solutions from $\mathrm{pH} 6$ to less than $\mathrm{pH} 8$, and borate buffer solutions at $\mathrm{pH} 8$ and 9. The concentration of buffer solution was prepared at $0.01 \mathrm{M}$. Data for the activity of lysozyme are the average of triple measurements. The relative activity was defined by the ratio of activity to maximum activity.

\subsection{Effect of Temperature on Activity and Stability of Free and Immobilized Lysozyme}

In order to examine the effect of temperature on the activity of free and immobilized lysozyme, the enzyme activity was measured in $\mathrm{pH} 6.2$ at various temperatures.

In order to evaluate the storage stability of free and immobilized lysozyme, the activity of free or immobilized lysozyme was measured after free or immobilized lysozyme was stored in $0.01 \mathrm{M}$ phosphate buffer solution at $\mathrm{pH} 6.2$ and $5^{\circ} \mathrm{C}$ for appropriate time. The residual activity was determined by the ratio of activity to initial activity.

In order to assess the thermal stability of free and immobilized lysozyme at high temperatures, the activity of free or immobilized lysozyme was measured after free or immobilized lysozyme was stored in $0.01 \mathrm{M}$ phosphate buffer solution at $\mathrm{pH} 7.0$ and $90^{\circ} \mathrm{C}$ for appropriate time, and then was cooled at $25^{\circ} \mathrm{C}$ for $30 \mathrm{~min}$. The residual activity was obtained by the ratio of activity after heat treatment to activity before heat treatment.

\section{Results and Discussion}

\subsection{Characterization of BCP}

The characteristics of the production process of $\mathrm{BCP}$ in the present work are indicated as follows: First, as plant biomass wastes are not burned in the process of pyrolysis, volatile carbon compounds such as phenols and lignin are gradually removed out, and nonvolatile carbon compounds are carbonized. Consequently, as seen in Figure 1, the morphology in $\mathrm{BC}$ of adzuki beans is kept, similar to that in native adzuki beans. Carbon dioxide emissions are reduced, and the atom economy of carbon is high, compared with the conventional production process of charcoal. Second, as the production process of BCP is carried out at low temperatures compared to the conven- 

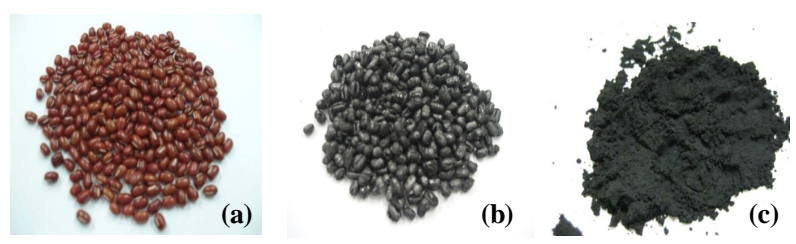

Figure 1. Photographs of BCP of adzuki beans: (a) Adzuki beans; (b) Biomass charcoal (BC) of adzuki beans obtained after adzuki beans were pyrolyzed; (c) Biomass charcoal powder (BCP) of adzuki beans obtained after BC was grinded.

tional production process of charcoal, the energy cost is held down. Thus, BCP is obtained at low costs by environmentally benign process, and has no toxicity.

Figure 2 shows the scanning electron micrograph of BCP of adzuki beans. As seen in the figure, the rough state like craters is observed on the surface of BCP of adzuki beans. BET surface area of BCP of adzuki beans was $204 \mathrm{~m}^{2} / \mathrm{g}$. The order of BET surface area of BCP was similar to that of the conventionally prepared charcoal [8]. The mean diameter of BCP was $7.3 \mu \mathrm{m}$. The $\zeta$ potential of BCP of adzuki beans was $-47.6 \mathrm{mV}$ at $\mathrm{pH} 7$. Figure 3 shows the ratio of elements of the surface of BCP detected by x-ray photoelectron spectroscopy (XPS). The main element is carbon, and oxygen and nitrogen atoms are also located on the surface of BCP of adzuki beans to some extent. From narrow scan spectra of XPS, the chemical states of carbon were mainly C-C and C-H, while as chemical states of carbon with oxygen and nitrogen, $\mathrm{C}-\mathrm{O}, \mathrm{O}-\mathrm{C}-\mathrm{O}, \mathrm{C}=\mathrm{O}, \mathrm{COOH}$, and $\mathrm{C}-\mathrm{N}$ were detected. These results indicate that $\mathrm{BCP}$ has the polar microenvironment on its surface. Accordingly, when BCP was added into an aqueous solution, BCP exhibited good wettability, and was steadily dispersed in an aqueous solution.

\subsection{Immobilization of Lysozyme on BCP}

We have employed lysozyme as a model protein. Figure 4 shows the time course of the amount of lysozyme adsorbed onto BCP of adzuki beans at $\mathrm{pH} 7$ and $25^{\circ} \mathrm{C}$. Amount of lysozyme adsorbed onto BCP of adzuki beans increased with an increase in adsorption time, reached a plateau around $24 \mathrm{~h}$, and was $11 \mu \mathrm{mol} / \mathrm{g}(0.16 \mathrm{~g} / \mathrm{g})$. As overall BCP concentration was $3 \mathrm{~g} / \mathrm{L}$ in an aqueous solution, overall lysozyme concentration in the aqueous solution corresponded to $33 \mu \mathrm{M}(0.48 \mathrm{mg} / \mathrm{mL})$. It is suggested that the adsorption of lysozyme on BCP is mainly attributed to the electrostatic interaction between the negative-charged BCP and the positive-charged lysozyme, since the isoelectric point of lysozyme is $\mathrm{pH} 11$. From the result, the adsorption of lysozyme onto BCP was carried out for $24 \mathrm{~h}$.

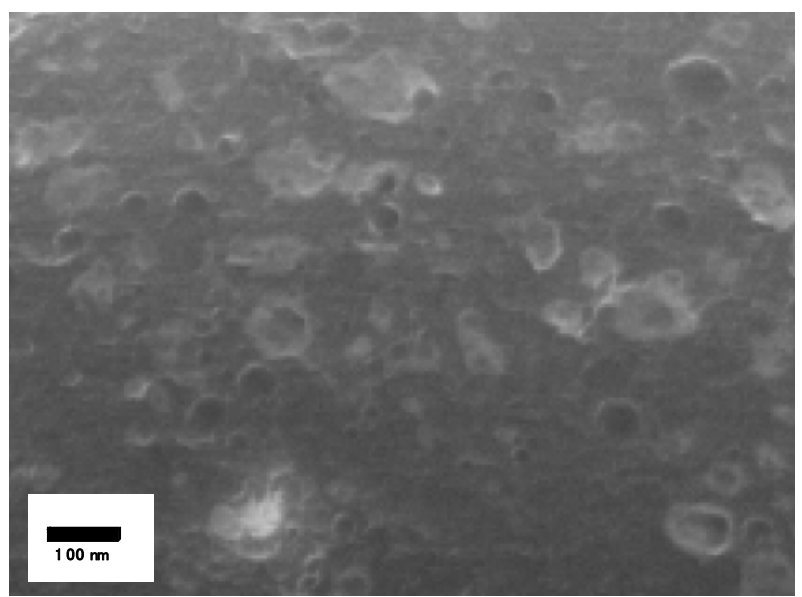

Figure 2. SEM image of BCP of adzuki beans.

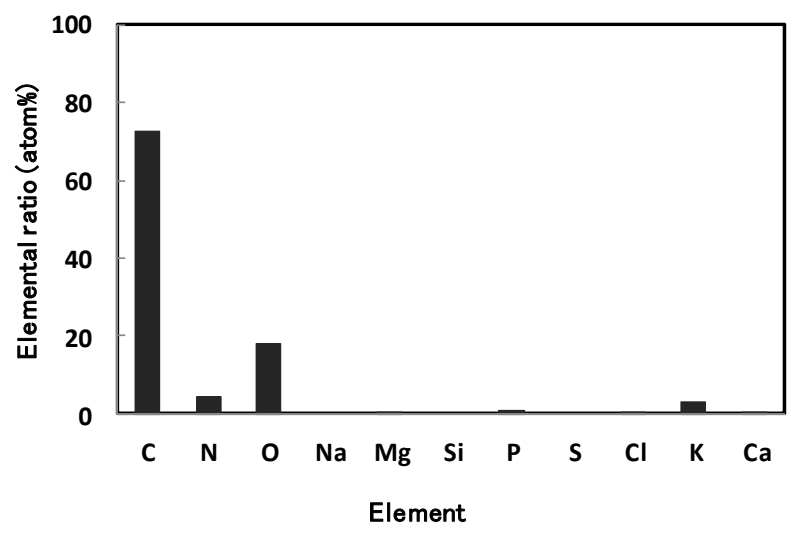

Figure 3. Elemental ratios (atom\%) of BCP of adzuki beans measured by XPS.

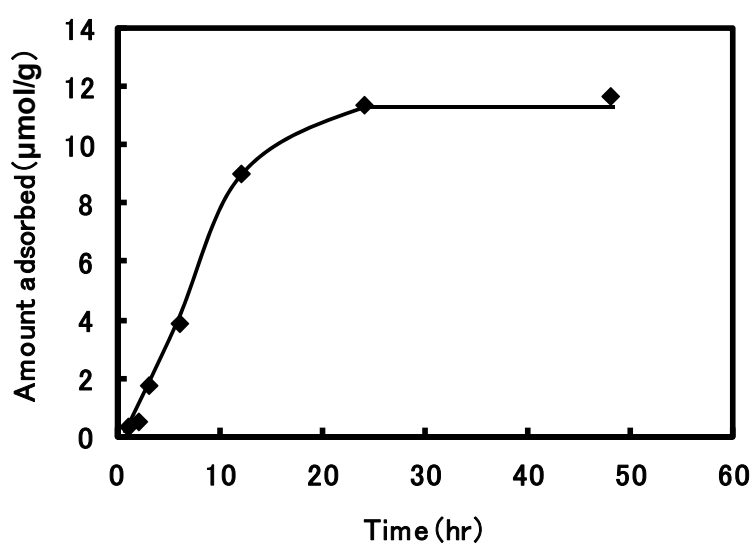

Figure 4. Time dependence of amount of lysozyme adsorbed on BCP of adzuki beans.

The activity of lysozyme immobilized on BCP of adzuki beans was $22100 \mathrm{U} / \mathrm{mg}$ of protein, while that of free lysozyme was $40200 \mathrm{U} / \mathrm{mg}$ of protein. Therefore, the effectiveness factor, which was defined as the ratio of the activity of lysozyme immobilized on BCP of adzuki beans to that of free lysozyme, exhibited 0.55 . 


\subsection{Effect of pH on Activity of Free and Immobilized Lysozyme}

The effect of $\mathrm{pH}$ on the activity of the free and immobilized lysozyme was assayed in the $\mathrm{pH}$ range from 5.0 to 9.0 at $25^{\circ} \mathrm{C}$. As shown in Figure 5, the optimum pH of immobilized lysozyme depicted $\mathrm{pH} 7.2$, while that of free lysozyme was $\mathrm{pH} 6.8$, similar to the case reported before [7]. The enzyme molecules possess basic, neutral, and acidic groups. Consequently, the intact enzyme contains both positively or negatively charged groups. The state of these ionic groups is influenced by the $\mathrm{pH}$ around enzyme molecules. Accordingly, the interaction between the surface of BCP and the reaction mixture needs to be taken into consideration. This interaction may cause the fluid environment adjacent to the surface in contact with the enzyme to differ substantially from the bulk fluid environment surrounding the immobilized enzyme [9]. For instance, a charged support will increase local concentrations of oppositely charged ions. In the present case, negative-charged BCP may increase local concentrations of hydrogen ions. As a result, the relationship between bulk solution $\mathrm{pH}$ and observed catalytic activity can be shifted to high $\mathrm{pH}$, compared to the $\mathrm{pH}$-activity function observed in solution, as seen in the figure.

\subsection{Effect of Temperature on Activity of Free and Immobilized Lysozyme}

The effect of reaction temperature on the activity of free and immobilized lysozyme was tested in the temperature range from $15^{\circ} \mathrm{C}$ to $55^{\circ} \mathrm{C}$ at $\mathrm{pH}$ 6.2. As shown in Figure 6, the optimum temperature for both free and immobilized lysozyme is found to be obtained at $25^{\circ} \mathrm{C}$. According to the Arrhenius equation, the initial rate becomes higher at higher temperatures, while the thermal denaturation of enzymes simultaneously proceeds with increasing temperature. Consequently, the profile of activity

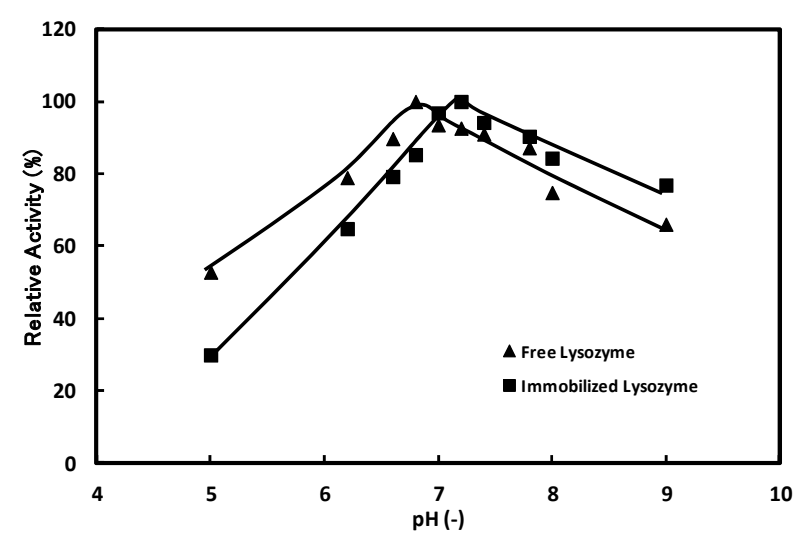

Figure 5. The effect of $\mathrm{pH}$ on the activity of free and immobilized lysozyme at $25^{\circ} \mathrm{C}$. The relative activity at optimum pH is taken as $100 \%$.

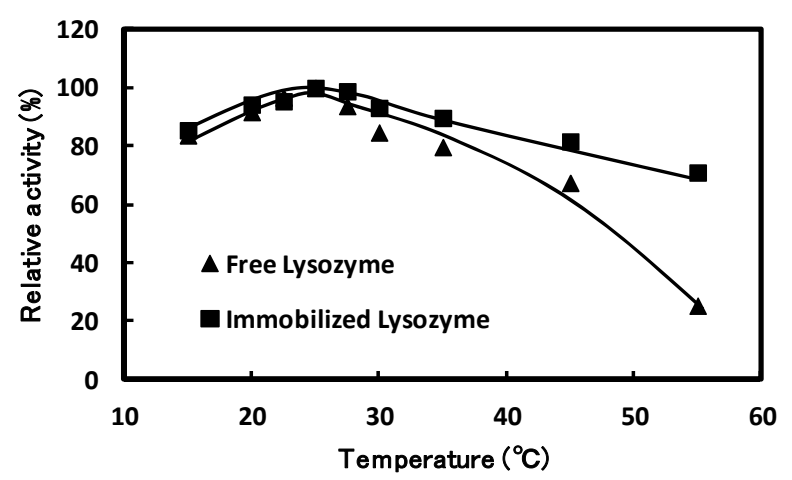

Figure 6. The effect of temperature on the activity of free and immobilized lysozyme at pH 6.2. The activity of free and immobilized lysozyme was measured in the temperature range from $15^{\circ} \mathrm{C}$ to $55^{\circ} \mathrm{C}$. The relative activity at optimum temperature is taken as $100 \%$.

exhibits an optimum temperature. At the optimum temperature or higher, the activity of immobilized lysozyme gradually decreased with increasing reaction temperature, whereas that of free lysozyme steeply dropped with increasing temperature. The interaction between the surface of BCP and the enzyme molecule may result in the maintenance of the activity of immobilized lysozyme.

\subsection{Storage Stability of Free and Immobilized Lysozyme}

Since the storage and applications of immobilized enzymes often need to be carried out in the artificial environment, which is extremely different from the physiological environment, it is important to investigate the storage stability of immobilized enzymes. Figure 7 shows time course of residual activity of free and immobilized lysozyme through the storage at $\mathrm{pH} 6.2$ and $5^{\circ} \mathrm{C}$. The residual activity of immobilized lysozyme was superior to that of free lysozyme. As seen in the figure, the relationship of the residual activities of free and immobilized lysozyme with storage time can be correlated by first-order kinetics. Table 1 represents rate constants and half lives of inactivation of free and immobilized lysozyme calculated from the fitting curves in Figure 7. The half-life of immobilized lysozyme was about twice longer than that of free lysozyme. This result indicates that immobilizing lysozyme onto BCP enhances the storage stability at low temperatures.

\subsection{Thermal Stability of Free and Immobilized Lysozyme}

Heating time directly enhances the thermal inactivation of proteins. Figure 8 shows time course of residual activity of free and immobilized lysozyme through the heat treatment at $\mathrm{pH} 7.0$ and $90^{\circ} \mathrm{C}$ as an accelerated test. Free lysozyme solution immediately became turbid due to the 
Table 1. Rate constants and half-lives of inactivation of lysozyme at $5^{\circ} \mathrm{C}$.

\begin{tabular}{ccc}
\hline Samples & Rate constant $\left(\mathrm{day}^{-1}\right)$ & Half life (day) \\
\hline Free lysozyme & 0.0625 & 14.3 \\
Immobilized lysozyme & 0.0485 & 26.2 \\
\hline
\end{tabular}

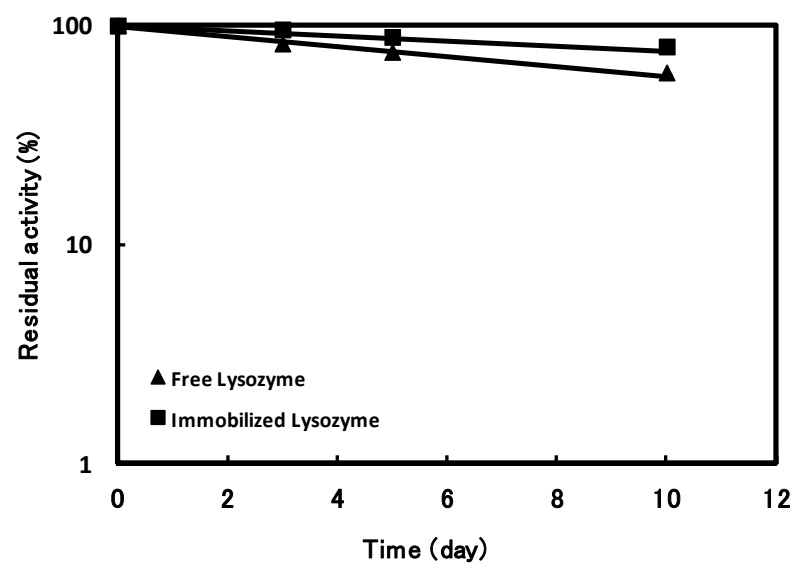

Figure 7. Time course of residual activity of free and immobilized lysozyme at $\mathrm{pH} 6.2$ and $5^{\circ} \mathrm{C}$.

formation in the aggregation of thermally-denatured proteins, as soon as heat treatment was carried out. On the other hand, the white protein aggregation and the cohesion among carriers immobilizing lysozyme were not observed in the solution dispersing immobilized lysozyme during the heat treatment. When proteins dissolved in an aqueous solution are placed at high temperatures, most of proteins are immediately unfolded due to the disruption of weak interactions including ionic effects, hydrogen bonds, and hydrophobic interactions, which are prime determinants of protein tertiary structures $[10,11]$. In addition, the intermolecular aggregation among unfolded proteins and the chemical deterioration reactions in unfolded proteins proceed. In particular, protein aggregation easily occurs upon the exposure of the hydrophobic surfaces of a protein, and this phenomenon becomes the major problem because of the fast irreversible inactivation. In the present work, immobilizing lysozyme onto BCP could inhibit the formation of protein aggregation. The residual activity of free lysozyme was almost lost for $30 \mathrm{~min}$, while that of immobilized lysozyme exhibited about $50 \%$. As seen in the figure, the relationship of the residual activities of free and immobilized lysozyme with heat treatment time can be correlated by first-order kinetics. Table 2 represents rate constants and half lives of inactivation of free and immobilized lysozyme calculated from the fitting curves in Figure 8. The half-life of immobilized lysozyme exhibited 7 -fold, compared to that of free lysozyme. The robust thermal stability of immobilized lysozyme may be
Table 2. Rate constants and half-lives of inactivation of lysozyme at $90^{\circ} \mathrm{C}$.

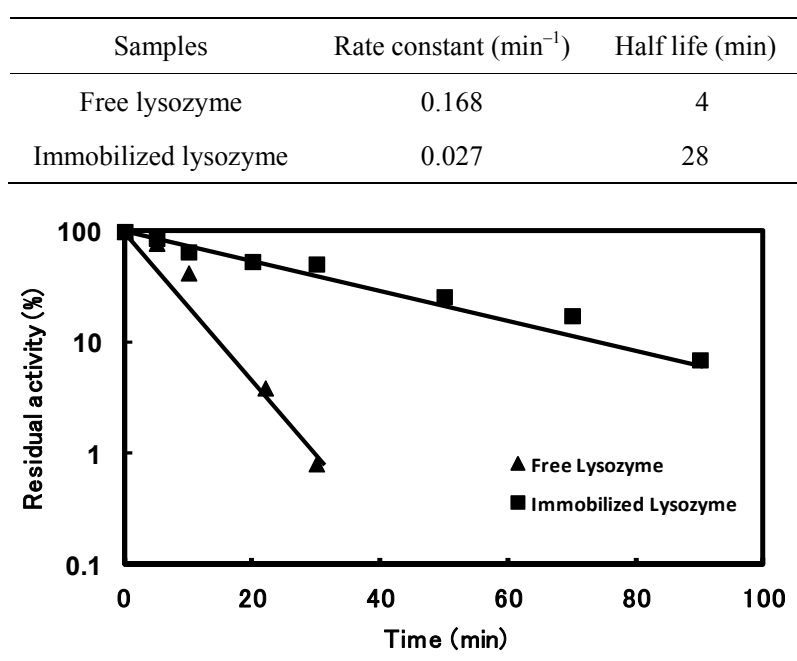

Figure 8. Time course of residual activity of free and immobilized lysozyme through the heat treatment at $\mathbf{p H ~} 7.0$ and $90^{\circ} \mathrm{C}$.

attributable to the suitable interaction of lysozyme with the surface of BCP.

Carriers immobilizing lysozyme do not attach each other through the heat treatment, indicating that the aggregation among thermally-denatured proteins immobilized on each carrier does not arise. On the other hand, if the aggregation of thermally-denatured proteins immobilized on the same carrier is formed, it is probably that more amount of lysozyme immobilized on BCP promotes the formation of protein aggregation, resulting on less residual activity. In order to elucidate the relation between the amount of lysozyme immobilized on BCP and the residual activity, the residual activity of immobilized lysozyme having a different immobilized amount was assayed after the heat treatment at $90^{\circ} \mathrm{C}$ for $30 \mathrm{~min}$. As seen in Figure 9, the residual activity shows around $50 \%$ regardless of the amount of lysozyme immobilized. This result indicates that the irreversible aggregation among thermally-denatured proteins immobilized on the same carrier hardly occurs under the present experimental condition.

\section{Conclusion}

$\mathrm{BCP}$ had polar functional groups such as carbonyl and carboxyl groups, and exhibited negative $\zeta$ potential at $\mathrm{pH}$ 7.0. Lysozyme was sufficiently immobilized on BCP of adzuki beans by adsorption. The optimum $\mathrm{pH}$ of immobilized lysozyme was higher than that of free lysozyme. The half-life of immobilized lysozyme exhibited 1.8 -fold compared to that of free lysozyme at $5^{\circ} \mathrm{C}$, while the half life of immobilized lysozyme was 7 times greater than that of lysozyme at $90^{\circ} \mathrm{C}$. The increase in stability 


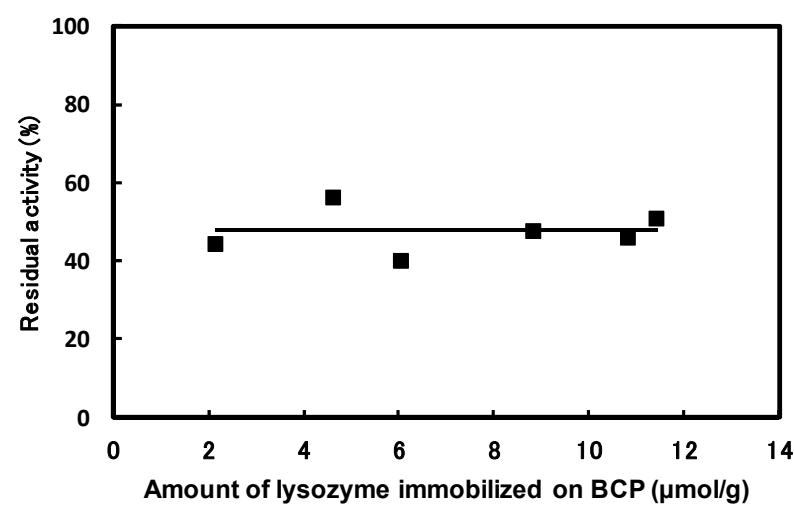

Figure 9. The effect of the amount of lysozyme immobilized on the residual activity of immobilized lysozyme after the heat treatment at $90^{\circ} \mathrm{C}$ for $30 \mathrm{~min}$.

shown by BCP-immobilized lysozyme would be encouraging for its choice in industrial application such as the sterilizing treatment.

\section{Acknowledgements}

This work was supported by a Grant-in-Aid for Scientific Research (C) from Japan Society for the Promotion of Science (No. 24561013) and a Grant-in-Aid for Scientific Research from Japan Science and Technology Agency (No. AS2111014D).

\section{REFERENCES}

[1] C. Mateo, J. M. Palomo, G. Fernandez-Lorente, J. M. Guisan and R. Fernandez-Lorente, "Improvement of Enzyme Activity, Stability and Selectivity via Immobilization Techniques," Enzyme and Microbial Technology, Vol. 40, No. 6, 2007, pp. 1451-1463. doi:10.1016/j.enzmictec.2007.01.018

[2] M. M. M. Elnashar, "Review Article: Immobilized Molecules Using Biomaterials and Nanobiotechnology," Jour- nal of Biomaterials and Nanobiotechnology, Vol. 1, No. 1, 2010, pp. 61-77. doi:10.4236/jbnb.2010.11008

[3] L. H. Noszko', A. Bo'ta, A'. Simay and L. G. Nagy, "Preparation of Activated Carbon from the By-Products of Agricultural Industry," Periodica Polytechnica, Vol. 28, 1984, pp. 293-297.

[4] J. Rivera-Utrilla, E. Ultera-Hidalgo, M. A. Ferro-Garcia and C. Mereno-Castilla, "Comparison of Activated Carbons Prepared from Agricultural Raw Materials and Spanish Lignites When Removing Chlorophenols from Aqueous Solution," Carbon, Vol. 29, No. 4-5, 1991, pp. 613-619. doi:10.1016/0008-6223(91)90128-6

[5] A. Cross and S. P. Sohi, "The Priming Potential of Biochar Products in Relation to Labile Carbon Contents and Soil Organic Matter Status," Soil Biology \& Biochemistry, Vol. 43, No. 10, 2011, pp. 2127-2134. doi:10.1016/j.soilbio.2011.06.016

[6] P. Jollès, "Lysozymes: Model Enzymes in Biochemistry and Biology," Birkhäuser Verlag, Basel, 1996.

[7] B. H. Ragatz, D. K. Werth and J. F. Bonner Jr., "Factors Influencing the Rate of an Enzyme Catalyzed Reaction: A Student Laboratory Experiment," Biochemical Education, Vol. 12, No. 2, 1984, pp. 60-64. doi:10.1016/0307-4412(84)90004-9

[8] H. Yano, M. Kiyama and K. Ueno, "Physical Properties Comparison and Functional Evaluation Examination of Charcoals," Kumamoto-Ken Hoken Kankyo Kagaku Kenkyushoho, Vol. 33, 2004, pp. 70-72.

[9] M. F. Chaplin and C. Bucke, "Enzyme Technology," Cambridge University Press, Cambridge, 1990.

[10] D. B. Volkin and A. M. Klibanov, "Minimizing Protein Inactivation,” In: T. E. Creighton, Ed., Protein Function: Practical Approach, IRL Press, Oxford, 1989, pp. 1-24.

[11] H. Noritomi, K. Minamisawa, R. Kamiya and S. Kato, "Thermal Stability of Proteins in the Presence of Aprotic Ionic Liquids," Journal of Biomedical Science and Engineering, Vol. 4, No. 2, 2011, pp. 94-99. doi:10.4236/jbise.2011.42013 